\title{
To greater heights!
}

\author{
Mauro Ferrari ${ }^{1}$
}

Published online: 10 March 2021

(c) The Author(s), under exclusive licence to Springer Science+Business Media, LLC, part of Springer Nature 2021

Dear BMMD Community - readers, authors, associate editors, reviewers, journal personnel, advertisers -dear all of you!

The tradition is to begin "goodbye" messages with something like: "It is with mixed emotions...." But BMMD has been a big tradition-breaker, in the 24 (twenty-four!) years of its operations, and I will stick with that tradition of non-tradition!

Tradition had it, that medicine and engineering were largely separate domains of human endeavor - and we broke away with that. And I am not surprised that we have ranked in the top ten biomedical engineering journals from day one.

Tradition had it, that microtechnology and silicon chips had nothing to do with medicine - and we broke away with that. As a matter of fact, this journal was born straight out of the very first class in BioMEMS ever taught anywhere in the world as far as I know - I envisioned and coordinated that class at UC Berkeley, and many in the journal Editorial Board gave lectures in that class. And some are still in it - they are the first group to whom I would like to express my gratitude!!!! Actually, some of the students that were in that class are now world-respected authorities, at great Universities all over the world - and are now members of the Editorial Board!

Tradition had it, that the words "nanotechnology" and "nanoscience" belonged in science fiction, not in science, and especially not in medicine! As the first academy journal to feature biomedical nanotechnology or nanomedicine in its title, we did break that tradition, did we not?

Tradition had it, that scientific manuscripts in frontier science would come mostly from a few regions of the world. While those great contributions are continuing to flow in, at BMMD now we are delighted to witness the powerful emergence of Countries that were underrepresented just a few years ago. We promoted that change, by establishing

Mauro Ferrari

mferrari@arrowheadpharma.com

1 Arrowhead Pharmaceuticals, Pasadena, CA, USA an especially designed editorial review system. We are delighted with that success!

Tradition had it, that Editorial Boards were essentially the province of senior, established faculty, almost exclusively at the full professor level. Academics of that caliber, including a strong cohort of National Academy members, continue to grace the Editorial Board of BMMD, and work actively in it. But at the same time, we have expanded it to encourage the engaged participation of a great group of brilliant young leaders. One of my greatest joys over the years has been to witness their splendid growth, into the highest level of academic excellence.

Tradition had it, that access to scientific discoveries was limited to a small number of professionals in the corresponding academic areas of knowledge. Now, the transition to Open Science, which we have actively encouraged, is fully democratizing access to groundbreaking science and technology.

So, hopefully you will forgive me for not being traditional, and starting this message with the words "mixed emotions", though my emotions are mixed, indeed! It has been twentyfour years together, from the very beginning of the journal. You, dear BMMD Community, have played a foundational role in launching those great fields of science and technology that are now benefiting millions of people in the clinic, and have become mainstays in the world of research and education, at all of the best academic institutions in the world. What a ride, what a joy, what a privilege for me to be able to provide my contributions, nanoscopic as they might have been! The words "I was humbled by the honor of serving you all" - traditional as it may sound - do come to my mind, from my heart, in full sincerity of emotions.

Any fields of endeavor need new blood, new leadership, new ideas, new perspectives, and as I am about to turn 62, I think the time has abundantly come, for me to step aside and let new leaders take this journal to greater heights, into the brilliant future it deserves. I have agreed with the Publisher's gracious request for me to stay on in an advisory capacity, and they were even more gracious, to offer me a distinguished title of honor, for which I am also grateful. 
I would have certainly been available to assist the journal leadership even without any title whatsoever, but of course it is nicer if the relationship is honored with some formality. So, thanks Springer-Nature for that, and for all the support throughout the years! Now it is time for me to concentrate on the clinical translation of new drugs and new devices, which were born out of the new sciences we have formed, together. I will do that from my entrepreneurial posts at DXT US, Arrowhead Pharmaceuticals, and BrYet Inc., and from my academic position in the Department of Pharmacy at the University of Washington.

As I conclude my journey as Editor-in-Chief of BMMD most of all, may I offer my heartfelt gratitude thanks to all of the authors that have trusted so many outstanding papers into our hands, and to the countless referees that have generously given of their time and talent to provide their expert reviews. Thanks to the Associate Editors - a truly unbelievable group of people, exceptionally successful, a veritable who's who of academic greatness, worldwide. Thanks to the personnel at Springer-Verlag for their invaluable help. And, of course thanks to all of our readers, worldwide!!!!

With great confidence in your continued, and actually expanded success, may I wish everyone the best - it has been a truly overwhelming honor, serving you all!

Mauro.

Publisher's Note Springer Nature remains neutral with regard to jurisdictional claims in published maps and institutional affiliations. 